\title{
Trioctylphosphine: A General Phosphorus Source for the Low- Temperature Conversion of Metals into Metal Phosphides
}

\author{
Amanda E. Henkes and Raymond E. Schaak*
}

Department of Chemistry, Texas A\&M University, College Station, TX 77842-3012
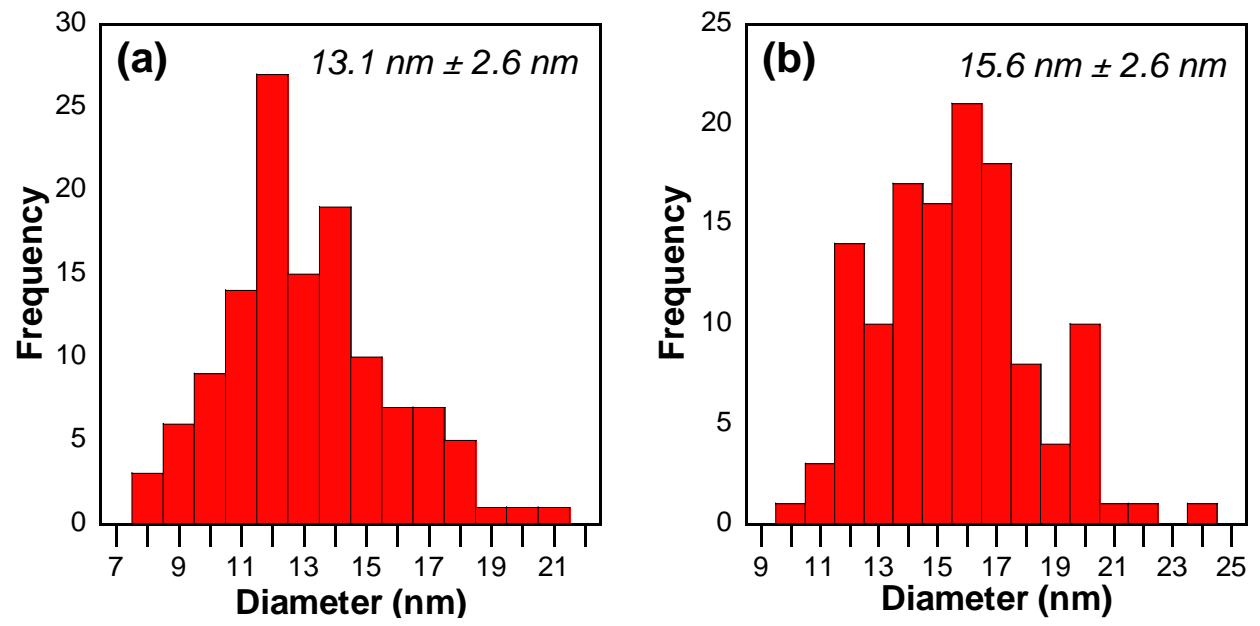

Figure S1. Histograms of nanoparticle diameters for (a) $\mathrm{Cu}$ and (b) $\mathrm{Cu}_{3} \mathrm{P}$ formed by reacting the $\mathrm{Cu}$ nanoparticles in (a) with TOP as described in the text. 


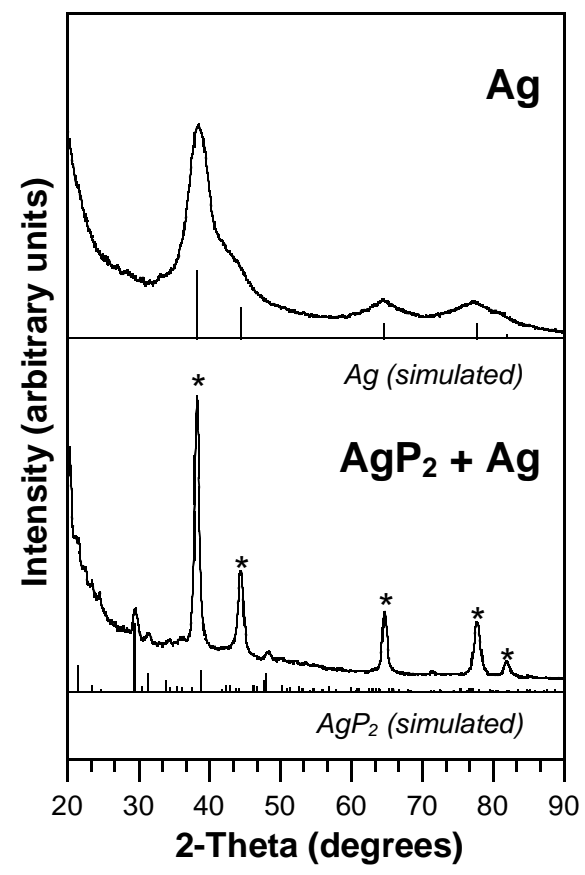

Figure S2. Powder $\mathrm{XRD}$ patterns for $\mathrm{Ag}$ nanoparticles and $\mathrm{AgP}_{2}$ formed from their reaction with hot TOP. Conversion in this system is low-yield (Ag represented by an asterisk).

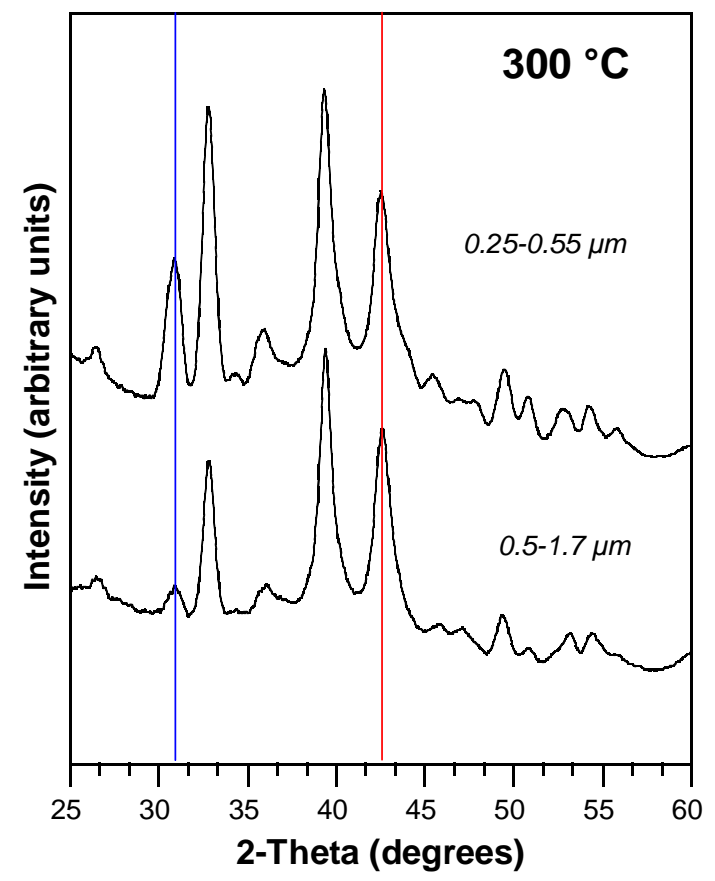

Figure S3. Dependence of Pd-P phase formation on Pd powder size for reaction with TOP at $300{ }^{\circ} \mathrm{C}$ for $2 \mathrm{~h}$. Blue and red lines correspond to non-overlapping $\operatorname{PdP}_{2}$ and $\operatorname{Pd}_{5} \mathrm{P}_{2}$ peaks, respectively, and can be used to approximate the relative amounts of each phase (discussed in text). 


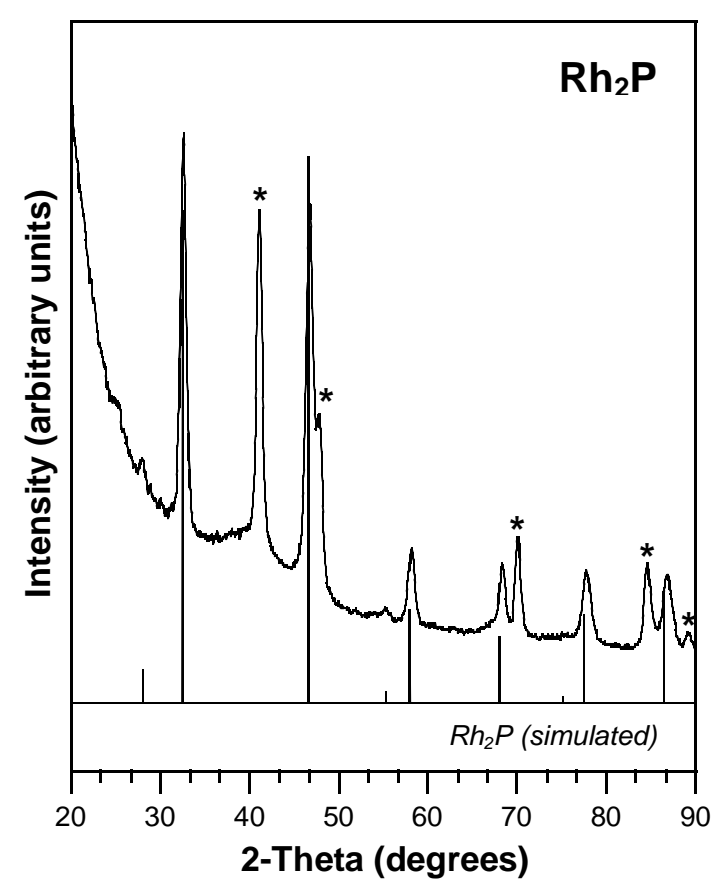

Figure S4. Powder $\mathrm{XRD}$ pattern for $\mathrm{Rh}_{2} \mathrm{P}$ formed by refluxing -325 mesh Rh powder in TOP. An asterisk represents a Rh metal impurity.
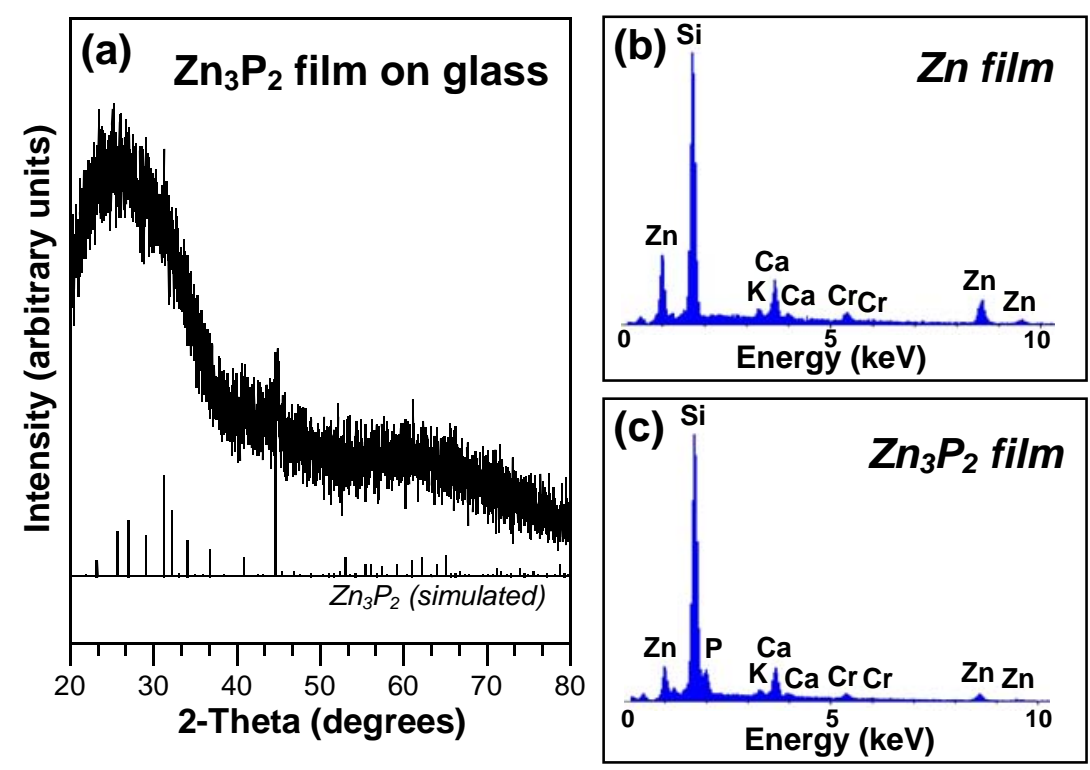

Figure S5. (a) Powder XRD pattern for $\mathrm{Zn}_{3} \mathrm{P}_{2}$ film on glass; EDS spectra for (b) $100 \mathrm{~nm} \mathrm{Zn}$ film on glass (with $10 \mathrm{~nm} \mathrm{Cr}$ adhesion layer) and (c) $\mathrm{Zn}_{3} \mathrm{P}_{2}$ film made by reacting the $\mathrm{Zn}$ film with hot TOP. ( $\mathrm{Si}$, Ca, and $\mathrm{K}$ are present in the glass substrate.) 


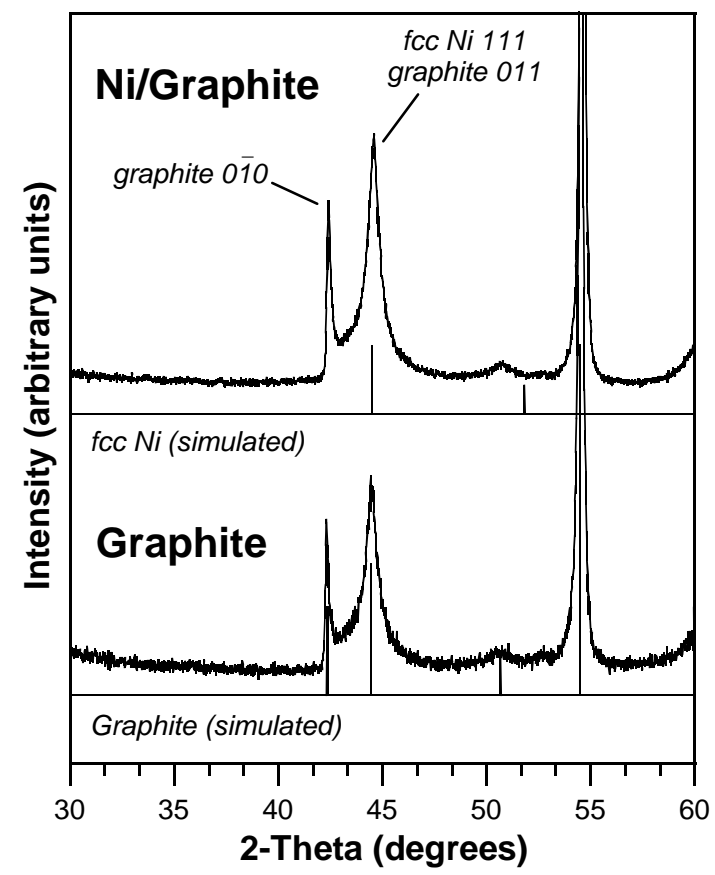

Figure S6. Powder XRD patterns for graphite-supported Ni nanoparticles and graphite (Alfa Aesar, conducting, -325 mesh). The relative ratios of the intensities of the graphite $0-10$ and 011 peaks suggest that fcc $\mathrm{Ni}$ is present, because the 111 peak of fcc $\mathrm{Ni}$ is superimposed over the graphite 011 peak and adds intensity. EDS and SAED data (discussed in text) further confirm this assignment. 